\title{
An Overview of Food Security Statuses in Afghan Refugees in Iran
}

\author{
Zahra Kamali ${ }^{1}$, Arezoo Haghighian Roudsari*2,3 ${ }^{2,}$ Abdol-Samad Abedi ${ }^{4}$, Fatemeh Mohammadi-Nasrabadi ${ }^{* 3}$ \\ 1- Faculty of Nutrition Sciences and Food Technology, National Nutrition and Food Technology Research Institute, Shahid Beheshti University of \\ Medical Sciences, Tehran, Iran \\ 2- Department of Community Nutrition, Faculty of Nutrition Sciences and Food Technology, National Nutrition and Food Technology Research \\ Institute, Shahid Beheshti University of Medical Sciences, Tehran, Iran \\ 3- Department of Food and Nutrition Policy and Planning, Faculty of Nutrition Sciences and Food Technology, National Nutrition and Food Technology \\ Research Institute, Shahid Beheshti University of Medical Sciences, Tehran, Iran \\ 4- Department of Research Deputy, Faculty of Nutrition Sciences and Food Technology, National Nutrition and Food Technology Research Institute, \\ Shahid Beheshti University of Medical Sciences, Tehran, Iran
}

\section{A B S T R A C T}

Background and Objectives: Refugees are often further susceptible to food insecurity in host countries. This study was carried out to review food insecurity statuses of Afghan refugees in Iran.

Materials and Methods: A comprehensive search was carried out using keywords of "food insecurity", "food security", "Iran", "Afghan", "immigrant" and "refugee" in English databases, including Scopus, Web of Science, PubMed and Google Scholar, as well as Persian databases, including Scientific Information Database, Noor, Magiran and Irandoc, from the beginning of 2000 to the end of 2019. Prevalence of food insecurity reported in each study was recorded based on the types of questionnaires and food insecurity criteria. Meta-analysis was carried out using random effect model with publication bias and heterogeneity tests using STATA Software.

Results: Overall, four studies were reviewed; of which, one was carried out in two provinces of Tehran and Mashhad. Household food insecurity access scale, United States Department of Agriculture and Radimer/Cornell questionnaires were used as the measurement tools in 2, 1 and 1 studies, respectively. Prevalence of mild, moderate and severe food insecurities was reported as 11.6-16.1, 27.4-46.5 and 20-61\%, respectively. Based on meta-analysis, prevalence of food insecurity in Afghan refugees in Iran was 89\% (95\% CI: 69-110\%). Food insecurity was significantly more prevalent in Afghan immigrants with illegal residential statuses and female-headed and bigger family size households. Being Sunnis, living in various cities (Tehran and Mashhad) and duration of staying in Iran were associated with food insecurity in Afghan refugees.

Conclusions: The high prevalence of food insecurity in Afghan refugees in Iran reveals the necessity of policies to limit the prevalence of food insecurity in these refugees in Iran.

Keywords: Food security, Afghan refugees, Immigrant, Iran, Review

\section{Introduction}

Food insecurity is defined as "ensuring physical and economic access to essential nutrients needed by all humans at all times for a healthy and active life" (1). Food insecurity is a major concern of the health issues and an indicator of health assessment and well-being (2). Refugees are often further susceptible to food insecurity in their host countries. Factors such as poor economics due to poverty, low-salary jobs, employment and educational insecurities, marginal and inappropriate social statuses and lack of valid immigration permissions are the factors that make immigrants susceptible to food insecurity $(3,4)$. Immigration is often a big crisis for the people and can change their lives, leading to malnutrition and food insecurity. Within the last three decades, a large number of Afghan refugees have entered Iran. Nowadays, more than 2.5 million Afghan refugees live in Iran, accounting for $3 \%$ of the total population of Iran (5). Of Afghan refugees residing in Iran, 97\% live in urban areas and 3\% in settlements and governmental and non-governmental organization camps (6). Data show that nearly one-third $(32.7 \%)$ of these immigrants live in Tehran Province (2015) and less than half of them (47\%) were women (5, 7). Factors such as ethnic or religious wars, unemployment, inflations and low socioeconomic statuses 
in Afghanistan are the most important factors for Afghan immigration to Iran. In contrast, factors such as security, geographical proximity, culture, religion and similar language are the most current reasons for the Afghans to migrate to Iran (8). The World Health Organization (WHO) concerns about immigrants' health, nutrition and access to healthy and adequate foods are socially acceptable (9). Despite the large number and long history of Afghan migration to Iran, little is known about their nutritional statuses (10). Therefore, the aim of the present study was to review literatures on food insecurity in Afghans living in Iran.

\section{Materials and Methods}

\section{Literature search}

This review study was carried out on food insecurity prevalence of Afghan refugees in Iran using searches in databases such as Scopus, PubMed, Web of Science, Google Scholar, Scientific Information Database (SID), Noor, Magiran and Irandoc in Persian and English languages (January 2001 to November 2019) and the following search criteria ("Food security"[All Fields] OR "Food insecurity"[All Fields]) AND ("Afghan"[All Fields] OR "migrant"[All Fields] OR "refugee"[All Fields] OR "Iran"[All Fields]).

\section{Article screening, data extraction and quality assessment}

Initial screening was carried out using titles and abstracts. Full texts were downloaded if needed. After searching the articles, they were selected and reviewed by the project executives to remove irrelevant items. Inclusion criteria were assessing food insecurity in Afghan refugees in various regions of Iran. Data extracted from the selected studies included author's name(s), publication year, sampling method and size, food insecurity measurement tools/questionnaires, food security criteria and various degrees of food insecurity.

\section{Data meta-analysis}

In the present study, meta-analysis was carried out only on total food insecurity prevalence in Afghan refugees, because studies have not been reported all degrees of food insecurity (mild, moderate and severe). Data was analyzed using STATA Software v.11.0 (STATA, College Station, TX, USA). Meta-analysis was carried out using random effect model with publication bias and heterogeneity testing with weighting of these studies. Prevalence of food insecurity in Afghan refugees in Iran was estimated at $95 \%$ confidence interval $(\mathrm{CI})$.

\section{Results}

In general, four studies were reviewed (8, 11-13); of which, one study was carried out in two provinces of Tehran and Mashhad (12). Table 1 shows characteristics of the studies on food security statuses of Afghan refugees in Iran. The sample size varied 150-414 and household food insecurity access scale (HFIAS), United States Department of Agriculture (USDA) and Radimer/Cornell questionnaires were used as the measurement tools in 2, 1 and 1 studies, respectively. Prevalence of mild, moderate and severe food insecurities was reported as 11.6-16.1, 27.4-46.5 and 20-61\%, respectively. The most heterogeneity was found in the prevalence of severe food insecurity. Based on the meta-analysis results from Fig. 1, prevalence of food insecurity in Afghan refugees in Iran was $89 \%$ (95\% CI: 69-110\%). Occupation, education and age of household heads and their wives, monthly incomes, house conditions and welfare facilities of the households were negatively associated to food insecurity. Food insecurity was significantly more prevalent in Afghan immigrants with illegal residential status $(8,12)$ as well as female-headed and bigger family size households (11-13). Being Sunnis, living in various cities (Tehran and Mashhad) (12) and duration of staying in Iran (12, 13) were associated to food insecurity in Afghan refugees.

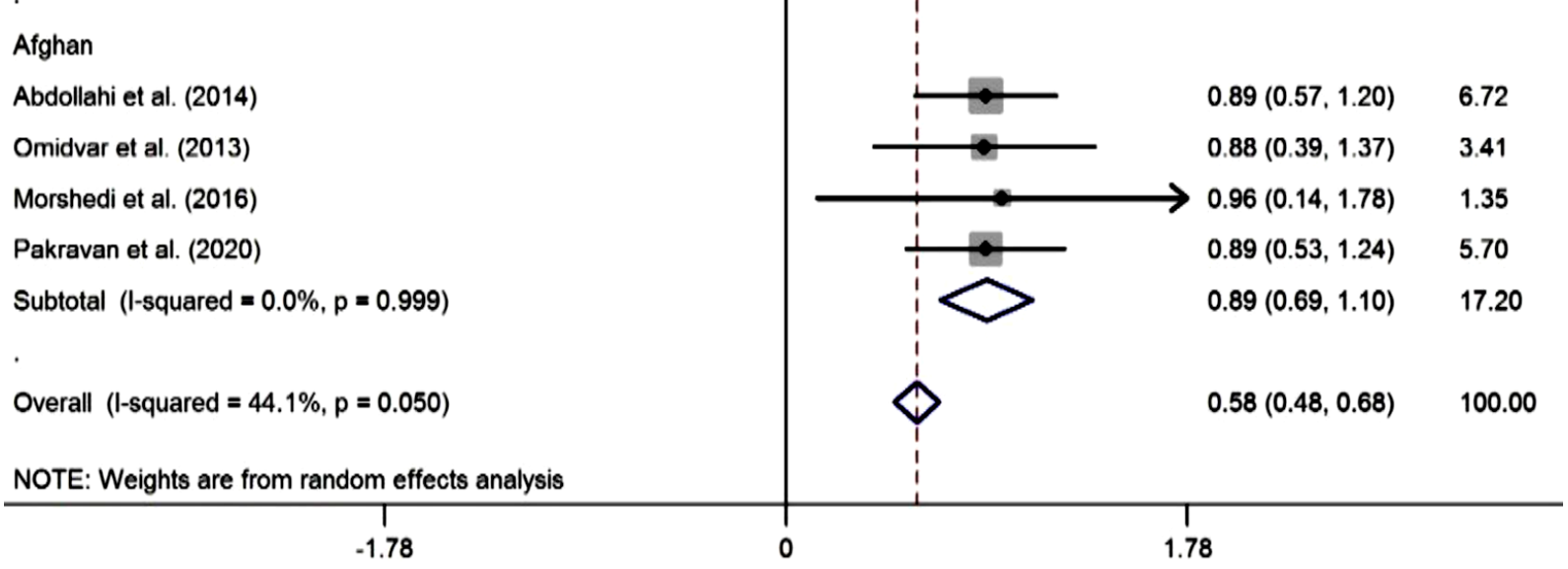

Figure 1. Overall prevalence of food insecurity in Afghan refugees in Iran 
Zahra Kamali, et al: Food security status among Afghan refugees

Table 1. Summary of studies on food insecurity of Afghan refugees

\begin{tabular}{|c|c|c|c|c|c|c|}
\hline $\begin{array}{l}\text { No. of } \\
\text { study }\end{array}$ & $\begin{array}{c}\text { Authors/year of } \\
\text { the study }\end{array}$ & Setting & Subjects/sampling & $\begin{array}{l}\text { Measurement } \\
\text { tool(s) }\end{array}$ & $\begin{array}{l}\text { Definition of food } \\
\text { insecurity }\end{array}$ & $\begin{array}{c}\text { Food insecurity } \\
\text { Prevalence (subgroup) } \%\end{array}$ \\
\hline 1 & $\begin{array}{l}\text { Abdollahi et al., } \\
2008 \text { (11) }\end{array}$ & $\begin{array}{c}\text { Afghan schools of } \\
\text { Pakdasht in the } \\
\text { neighborhood of } \\
\text { Tehran }\end{array}$ & $\begin{array}{l}414 \text { Afghan } \\
\text { households/ }\end{array}$ & $\begin{array}{c}\text { USDA food security } \\
\text { assessment } \\
\text { questionnaire }\end{array}$ & $\begin{array}{l}\text { Food security } \\
\text { Mild } \\
\text { Moderate } \\
\text { Severe }\end{array}$ & $\begin{array}{c}11.2 \\
- \\
27.4 \\
61\end{array}$ \\
\hline 2 & $\begin{array}{l}\text { Omidvar et al., } \\
2012 \text { (12) }\end{array}$ & $\begin{array}{l}\text { Tehran and } \\
\text { Mashhad city }\end{array}$ & $\begin{array}{l}310 \text { Afghan } \\
\text { households/ } \\
\text { multistage } \\
\text { sampling }\end{array}$ & HFIAS & $\begin{array}{l}\text { Food security } \\
\text { Mild } \\
\text { Moderate } \\
\text { Severe }\end{array}$ & $\begin{array}{l}22.9 \\
13.9 \\
42.9 \\
20.3\end{array}$ \\
\hline 3 & $\begin{array}{c}\text { Morshedi and } \\
\text { Maarefvand, } 2016 \\
\text { (8) }\end{array}$ & $\begin{array}{c}\text { Farahzad and } \\
\text { Shahrerey of Tehran } \\
\text { city }\end{array}$ & $\begin{array}{l}150 \text { Afghan } \\
\text { households/ } \\
\text { simple sampling }\end{array}$ & Radimer-Cornel & $\begin{array}{l}\text { Food security } \\
\text { Household } \\
\text { Adult } \\
\text { Child }\end{array}$ & $\begin{array}{c}- \\
96 \\
93 \\
84.7\end{array}$ \\
\hline 4 & $\begin{array}{c}\text { Pakravan and } \\
\text { Mohammadi- } \\
\text { Nasrabadi, } 2019 \\
\text { (13) }\end{array}$ & $\begin{array}{l}\text { Southern areas of } \\
\text { Tehran province }\end{array}$ & $\begin{array}{l}317 \text { Afghan } \\
\text { households/ } \\
\text { simple random } \\
\text { sampling }\end{array}$ & HFIAS & $\begin{array}{l}\text { Food security } \\
\text { Mild } \\
\text { Moderate } \\
\text { Severe }\end{array}$ & $\begin{array}{l}11.3 \\
11.7 \\
40.7 \\
36.3\end{array}$ \\
\hline
\end{tabular}

\section{Discussion}

In the current study, prevalence of food insecurity was estimated $89 \%$ in Afghan refugees residing in Iran. A meta-analysis of experiential/perception based studies between 1991 and 2011 in Iran revealed lower rates of moderate $(14.9 \%)$ and severe $(6.0 \%)$ FI in Iranian households, respectively (14). However, in a study by Omidvar et al. (15) on data from 2016 Gallup World Poll (GWP), prevalence of moderate and severe FI in Iran and Afghanistan was reported as 47.4 and $39.4 \%$, respectively. Furthermore, prevalence of household food insecurity in Canada was higher in recent immigrant households of less than five years in Canada $(10.9 \%)$, compared to nonrecent immigrant households (7.6\%) (16). Food insecurity has gradually decreased over the years, with the prevalence of food insecurity in immigrants reaching nearly the national level after ten years (17-19). Food insecurity, dietary acculturation and inadequate access to healthcare were major contributing factors to newcomer health. Newcomer health decreased over time, which could increase burdens on the Canadian healthcare system. In general, a limited information is available on the relationships between food security and social determinants of heath and how these relationships affect unique subgroups of newcomers. Further studies are needed to culturally identify appropriate and cost-effective ways to promote traditional foods and to assess nutritional quality and safety in Canada (20, 21). However, Khakpour et al. (22) reported that food insecurity was a consistent condition for Afghan refugee families in Pakistan regardless of their length of staying.

Data from 2001-2011 Restricted California Health Interview Survey $(n=245,679)$ showed prevalence of food insecurity in white residents (7-9\%) and Asian
Americans (5-9\%) increased to $11 \%$ in 2011 for the two populations. Moreover, food insecurity was higher in illegal immigrants and Asian Americans than white Americans. It was estimated that one in four Latino immigrants and one in five Asian immigrants in California reported food insecurity, even after considering program assistance, English language proficiency and duration of residence (55). Chilton et al. (23) compared risks of household food insecurity and poor health in young children from immigrant $(n=7216)$ and native mothers in US, 1998-2005. Increased risks of fair or poor health and food insecurity were reported in children of recent immigrant households, compared to those in children of US-born mothers $(p<0.05)$. Household food insecurity increased risks of fair or poor child health $(p<0.001)$ and mediated associations between the immigrant status and poor child health. Participations in Food Stamp Program and Special Supplemental Nutrition Program for Women, Infants and Children (WIC) in US-born mothers were respectively higher and lower than that of immigrants. Another study in US by Miller et al. (24) investigated the longitudinal trends of FI in children of immigrants using growth curve modeling and data from 1998 Early Childhood Longitudinal Study-Kindergarten Cohort. The researchers found that children of immigrants included significantly higher initial rates of FI than children of US households. These rates increased significantly over the time; however, rates were slower in next generations. All differences were mediated by poverty. Based on these findings, interventions addressing food insecurity in immigrant households must be carried out to promote child health, considering cultural aspects (25). 
Based on cultural food insecurity concept, which is assessed at three levels of food availability, accessibility and use, high costs or variations in tastes of particular foods in every culture may increase food insecurity in immigrants and refugees. Their inabilities to procure and consume alien foods may damage cultural values regarding food consumption. This can be a potential determinant of cultural identity loss that may affect individual mental health. In addition, cultural food insecurity can determine immigrants' dietary changes to unhealthy diets resulted in non-communicable and nutritional-linked illnesses. Therefore, cultural food insecurity can lead to deteriorating health and well-being of immigrants and refugees (26). Although foods in Canadian urban centers are tailored to various cultures, access to foods through low-processed, healthy favorite ways is difficult. Many immigrants were worried about where and how their foods were prepared. Use of pesticides and fertilizers, availability of Halal products for particular cultures and lack of easy access to organic foods due to their high costs have been major concerns of immigrants and refugees in Canada. Furthermore, it is important that many immigrants do not have the proper knowledge of healthy foods and need financial supports, especially within the first five years of entry, to achieve healthy and adequate foods $(26,27)$.

Causes of high FI in Afghan immigrant households were not studied in this study. Based on the previous studies on food insecurity in immigrants and refugees, especially Afghans, causes could mostly be attributed to employment in low-level jobs which might lead to low salaries for the head of households and hence low incomes for the families. Stress and anxiety of immigrants and overwhelming efforts to have a normal life with other indigenous families in the country, urge the immigrants to ask jobs that need low skills and wages. In addition, most immigrants enter countries illegally and thus do not receive social and economic protections from the governments. In fact, immigrants are not able to live comfortably because of unfamiliarity with the new environments and sense of unfamiliar identities. Traditional foods and various livelihoods from ethniccultural identities custom the nations, which are endangered by the immigration (49). Based on several studies, food insecurity is more prevalent in low-income immigrants, especially in unskilled ones, and is strongly associated to lower consumptions of fruits and vegetables, resulting in lower intakes of micronutrients $(2,24,28,29)$.

\section{Limitations}

To the best of the authors' knowledge, this is the first study reviewing all studies on FI in Afghan refugees in Iran. However, limitations were reported in this study, which might affect results of the review. A major limitation of the study included the little number of published studies (only four) on FI in Afghan households. Moreover, studies were majorly limited to Tehran Province and only a study on Afghans FI was partially carried out in cities other than Tehran. This made generalizability of the study results difficult in Iran as well as other countries. Low quality and heterogeneity of the studies could be reported as other limitations of the current study.

\section{Conclusion}

Based on the literature reviews, almost 90\% of Afghan immigrant households in Iran are food insecure. The high prevalence of food insecurity, especially severe FI, in Afghan refugees in Iran reveals the necessity of legal policies to limit the prevalence of food insecurity in these groups. Furthermore, studies on the underlying causes of food insecurity in Afghan refugees seem necessary. Nutrition and stress management educations for the better food selections, equal job opportunities and modification of legal regulations on using Afghan immigrants in various jobs can be helpful as well.

\section{Acknowledgement}

This review was carried out in National Nutrition and Food Technology Research Institute (NNFTRI), Tehran, Iran. The authors thank the Research Deputy of NNFTRI and all the researchers who helped the current review.

\section{Financial disclosure}

The authors declared no financial interest.

\section{References}

1. FAO. Rome Declaration on World Food Security and World Food Summit Plan of Action: World Food Summit 13-17 November 1996, Rome, Italy: Food and Agriculture Organization; 1996.

2. Hadley C, Zodhiates A, Sellen DW. Acculturation, economics and food insecurity among refugees resettled in the USA: a case study of West African refugees. Public Health Nutrition. 2007;10(4):405-12.

3. Ramesh T, Dorosty Motlagh A, Abdollahi M. Prevalence of household food insecurity in the City of Shiraz and its association with socio-economic and demographic factors, 2008. Iranian Journal of Nutrition Sciences \& Food Technology. 2010;4(4):53-64.

4. Renzaho A, Renzaho C, Polonsky M. Left out, left off, left over: why migrants from non-English speaking backgrounds are not adequately recognised in health promotion policy and programs. Health promotion journal of Australia. 2012;23(2):84-5.

5. United Nations. International migration report 2017: UN; 2018.

6. Naseh M, Potocky M, Stuart PH, Pezeshk S. Repatriation of Afghan refugees from Iran: a shelter profile study. Journal of International Humanitarian Action. 2018;3(1):13. 
7. Abbasi-Shavazi M, Sadeghi R. The Adaptation of Secondgeneration Afghans in Iran: Empirical Findings and Policy Implications. MEI-FRS Research Paper. International Migration. 2015;53(6):89-110.

8. Morshedi SZ, Maarefvand M. Afghan Immigrant Women's Food Security in Farahzad and Shahrerey. Quarterly Journal of Social Work. 2016;5(1):34-40.

9. WHO. Health of refugees and migrants: Situation analysis and practices in addressing the health needs of refugees and migrants: Examples of public health interventions and practices. WHO Eastern Mediterranean Region, 2018.

10. Sheykholeslam R, Abdollahi Z, Salarkia N, Kavehi Z, Abdollahi M, Kalantari N. Food security assessment of urban Afghan refugee populations in Pakdasht, Iran. Tehran: World Food Program. 2008;38.

11. Abdollahi M, Abdollahi Z, Sheikholeslam R, Kalantari N, Kavehi Z, Neyestani TR. High occurrence of food insecurity among urban Afghan refugees in Pakdasht, Iran 2008: a cross-sectional study. Ecology of food and nutrition. 2015;54(3):187-99.

12. Omidvar N, Ghazi-Tabatabie M, Sadeghi R, Mohammadi F, Abbasi-Shavazi MJ. Food insecurity and its sociodemographic correlates among Afghan immigrants in Iran. Journal of health, population, and nutrition. 2013;31(3):356.

13. Pakravan Charvadeh M, Mohammadi-Nasrabadi F. The association between social welfare, food security and diet diversity among Afghan immigrant households in the Southern areas of Tehran province. Iranian Journal of Nutrition Sciences \& Food Technology. 2020.

14. Mohammadi Nasrabadi F, Omidvar N, Khoshfetrat M, Kolahdooz F. Household food insecurity in the Islamic Republic of Iran: a systematic review and meta-analysis. Eastern Mediterranean Health Journal. 2014;20(11):698-706.

15. Omidvar N, Ahmadi D, Sinclair K, Melgar-Quiñonez H. Food security in selected Middle East and North Africa (MENA) countries: an inter-country comparison. Food Security. 2019;11:531-40.

16. Statistics-Canada. Household food insecurity in Canada statistics and graphics (2011 to 2012). Canada: Health Canada's Office of Nutrition Policy and Promotion, 2013.

17. Girard A, Sercia P. Immigration and food insecurity: social and nutritional issues for recent immigrants in Montreal, Canada. International Journal of Migration, Health and Social Care. 2013.
18. Rush TJ, Ng V, Irwin JD, Stitt LW, He M. Food insecurity and dietary intake of immigrant food bank users. Canadian Journal of Dietetic Practice and Research. 2007;68(2):73-8.

19. Tarasuk V. Household food insecurity in Canada. Topics in Clinical Nutrition. 2005;20(4):299-312.

20. Lane G, Nisbet C, Vatanparast H. Food Insecurity and Nutritional Risk among Canadian Newcomer Children in Saskatchewan. Nutrients. 2019;11(8):1744-61.

21. Vatanparast H, Nisbet C, Patil R. Food Security and Nutritional Health of Newcomer Children. In: Preedy V, Patel V, editors. Handbook of Famine, Starvation, and Nutrient Deprivation. Cham: Springer; 2017.

22. Khakpour M, Iqbal R, GhulamHussain N, Engler-Stringer R, Koc M, Garcea J, et al. Facilitators and Barriers toward Food Security of Afghan Refugees Residing in Karachi, Pakistan. Ecol Food Nutr 2019;58(4):317-34

23. Chilton M, Black MM, Berkowitz C, Casey PH, Cook J, Cutts D, et al. Food insecurity and risk of poor health among US-born children of immigrants. American journal of public health. 2009;99(3):556-62.

24. Miller DP, Chang J, Ha Y, Martinez LS. Longitudinal trajectories of food insecurity among children of immigrants. Journal of immigrant and minority health. 2018;20(1):194202.

25. Greenwald HP, Zajfen V. Food Insecurity and Food Resource Utilization in an Urban Immigrant Community. J Immigrant Minority Health. 2015;19(1):179-86.

26. Moffat T, Mohammed C, Newbold KB. Cultural dimensions of food insecurity among immigrants and refugees. Human Organization. 2017;76(1):15-27.

27. Tarraf D, Sanou D, Giroux I. Immigration and Food Insecurity: The Canadian Experience-A Literature Review. 2015. In: People's Movements in the 21st Century: Risks, Challenges and Benefits [Internet]. Groatia: Intch.

28. Hadley C, Galea S, Nandi V, Nandi A, Lopez G, Strongarone $\mathrm{S}$, et al. Hunger and health among undocumented Mexican migrants in a US urban area. Public Health Nutrition. 2008;11(2):151-8.

29. Vahabi M, Damba C, Rocha C, Montoya EC. Food insecurity among Latin American recent immigrants in Toronto. Journal of immigrant and minority health. 2011;13(5):929-39. 